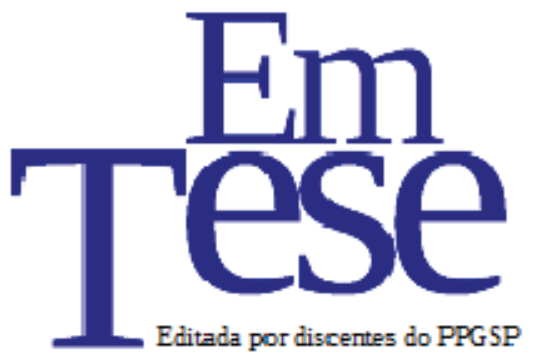

UFSC

PPG SP PROG RAMA DE PÓS-GRADUAÇÃO EM Sociologia Política

\title{
Partidos e competição eleitoral nas eleições de 2014 em Moçambique
}

\author{
Fidel Terenciano ${ }^{1}$ \\ Maria Do Socorro Souza Braga ${ }^{2}$ \\ Carlos Augusto da Silva Souza ${ }^{3}$
}

Resumo: O artigo tem como objetivo analisar as dinâmicas das eleições de 2014 em Moçambique. Desde 1994, Moçambique vive uma democracia eleitoral e as eleições são os mecanismos para a escolha e a substituição dos dirigentes de cinco em cinco anos. O pressuposto é que as eleições de 2014 corroboraram com as evidências dos pleitos anteriores que indicam a existência de padrões de dominância na distribuição da geografia eleitoral de Moçambique, entre o partido governista, FRELIMO, e o principal partido da oposição, RENAMO. Desenvolvemos o artigo a partir da abordagem combinada (qualitativa e quantitativa), tendo um caráter descritivo, fundamentado pelos resultados das eleições de 2014 e relacionamos com os níveis de escolaridade nos distritos eleitorais de Moçambique. Os resultados da nossa análise mostram que, nas regiões de dominância do partido RENAMO, houve um avanço significativo nos níveis de consciência cívica explicada a partir do aumento de escolaridade nas tais regiões. Verificou-se pela primeira vez que os eleitores nas regiões supracitadas, atribuíram seu voto de forma diferenciada, tanto para o partido, quanto para o candidato, sendo que o voto não ocorreu para o candidato partidário. Ao mesmo tempo, propomos que Moçambique carece de uma Reforma Política-Eleitoral como forma de aproximar os eleitores e candidatos.

Palavras-chave: Eleições, Partidos Políticos, Moçambique.

\section{Parties and electoral competition in 2014 elections in Mozambique}

Abstract: The article, aim to an analysis of the dynamics of the elections of 2014 in Mozambique. From 1994, Mozambique lives a electoral democracy, and the elections are the mechanism for election and replacement of the leaders in 5 to 5 years bases. The assumption is that the elections of 2014 have corroborated with the evidence of the previous elections that indicate the existence of patterns of dominance in the

\footnotetext{
${ }^{1}$ Doutorando em Ciência Política na UFSCar. Mestre em Ciência Política na UFPA e Graduado em Ciência Política na Universidade Eduardo Mondlane - Moçambique. E-mail: fideldeanarosa@ gmail.com.

${ }^{2}$ Pós-Doutora em Ciência Política pela Universidade de São Paulo. Professora na Universidade Federal São Carlos, no Programa de Pós Graduação em Ciência Política. Integra, desde julho de 2012, a diretoria da Associação Brasileira de Ciência Política (ABCP) e é pesquisadora da FAPESP e CNPq. E-mail: msbraga2009@gmail.com.

${ }^{3}$ Doutor em Ciência Política pelo Instituto Universitário de Pesquisas do Rio de Janeiro - IUPERJ, Professor na Universidade Federal do Pará, no Programa de Pós Graduação em Ciência Política, onde exerce atualmente a função de Coordenador do curso. E-mail: carlossouza@ufpa.br.
} 
distribution of electoral geography in Mozambique between the ruling FRELIMO and the main opposition party RENAMO. We have developed the article from the combined approach (qualitative and quantitative), and had the character descriptive, based on the 2014 elections result, and relate to the variable schooling in the electoral districts of Mozambique. The results of our analysis show that in the regions of dominance of the party RENAMO, there was a breakthrough in the levels of civic consciousness explained from the increase in schooling in these regions. It verified for the $1^{\mathrm{a}}$ time that the constituents in the regions indicated, attribute his vote of form differentiated to the party and the same does not become for the candidate adherent. And propose that Mozambique lacks a Political Reform-Electoral like form to approximate the electors and candidates.

Keywords: Elections, Political Parties, Mozambique.

\section{Introdução}

O ritual chamado eleições é um jogo da reengenharia institucional (SARTORI, 1999) que permite selecionar os vencedores e os derrotados em cada região ou país. Em Moçambique não acontece diferente, as eleições que, em norma são realizadas de cinco em cinco anos, representam um estágio da renovação da elite política e os representantes parlamentares como um todo. Em 1992, foi aprovada a $1^{\text {a }}$ Lei Eleitoral de Moçambique, que seguiu os princípios da Constituição da República de 1990 e o III $^{\circ}$ protocolo dos Acordos Gerais de Paz (AGP), o qual previa a eleição do presidente da república por via do voto majoritário e dos parlamentares por representação proporcional dos votos obtidos na escala nacional (CARRILHO, 1995; TERENCIANO, 2016).

As eleições de 2014 foram as primeiras na história política do país, que permitiram o fortalecimento da terceira força política no parlamento, neste caso, o Movimento Democrático de Moçambique (MDM), que conseguiu entre +9 assentos, ou $+110 \%$ dos seus assentos parlamentares, se comparado com o seu desempenho eleitoral em 2009. De outra forma,o partido Resistência Nacional de Moçambique (RENAMO) recuperou os assentos que perdera em 2009, doravante o partido Frente de Libertação de Moçambique (FRELIMO) perdeu parte considerável dos assentos parlamentares. Apesar deste revés, os resultados eleitorais de 2014 seguiram uma tendência contrária sobre o fortalecimento do MDM, isto porquê, o MDM competiu de forma direta com o 
partido governista desde a independência de Moçambique, a FRELIMO. Nas eleições municipais de 2013, destacando Gurué, Nampula, Quelimane, Beira, Maputo e Matola ${ }^{4}$.

Este artigo tem como objetivo problematizar os resultados eleitorais de 2014, procurando demonstrar as dinâmicas da competição política e geográfica eleitoral de Moçambique, incluindo a variável escolaridade como determinante do avanço dos níveis de consciência cívica. É importante destacar que surgiram novas dinâmicas no campo político moçambicano, no qual se verificou, pela primeira vez, que os eleitores de algumas regiões do país, atribuíram seu voto ao candidato do partido RENAMO, Afonso Dhlakama, porém, não atribuindo o voto ao partido a qual pertence Dhlakama. Em seguida, buscamos verificar a geografia eleitoral da vitória do candidato presidencial da FRELIMO, Filipe Nyusi, com pretensões de descrever sequencialmente as zonas de dominância nos termos da distribuição geográfica dos votos. Por fim, o artigo apresenta algumas possibilidades de uma reforma política eleitoral em Moçambique, como resultado dos processos políticos no país como um todo.

Debates teóricos e conceituais sobre a competição política e eleitoral têm sido explorados intensamente na ciência política desde os anos 50 do século XX. Existem diversas correntes que buscam explicar as razões determinantes das tendências da competição eleitoral e preferências eleitorais, que são resultantes do contexto histórico e do ambiente social (ANTUNES, 2008; BARTELS, 1996; FIGUEIREDO, 2008; ROSEMA, 2004), das condições da economia e da racionalidade individual (DOWNS, 1957; COX, 1997; HARDER e KROSNICK, 2008; KALIL, 2009), em que se destaca o voto retrospectivo (FIORINA, 1976) e prospectivo (KEY Jr. 1966) e também, resultante da identidade social ou identificação partidária (ANTUNES, 2008; BOND et al., 2012).

Apesar das diversas explicações sobre as preferências eleitorais e competição política, destacamos alguns pressupostos teóricos que serão o nosso embasamento analítico: a corrente da Cultura Cívica - Política (ALMOND E VERBA, 1963; INGLEHART, 1990; 2005; FRANKLIN, MACKIE E VALEN, 1992; PUTNAN, 1993; DALTON, 1992; DALTON E KLINGEMANN, 2009; PIPPA, 2009) fundamentada especialmente pela teoria da modernização social (DALTON, 1992; PIPPA, 2009),

\footnotetext{
${ }^{4}$ Nestas eleições municipais, o principal partido da oposição, a RENAMO, não participou e o partido MDM, teve um maior espaço para a competição, se aproximando do espaço pragmático deixado pela RENAMO. Dos municípios mencionados, o MDM venceu em três dos cinco principais municípios de Moçambique (Beira, Quelimane, Nampula).
} 
associada com as abordagens da institucionalização da competição partidária (PEREZ, 2013; MAIR, 1997; ELDERSVELD, 2000).

Os teóricos que fundamentam a relação entre níveis de escolaridade e consciência política dos cidadãos, tal como Almond e Verba (1963), demonstraram que as sociedades onde os cidadãos têm a capacidade de questionar de forma valorativa os outputs do governo, seriam as mais próximas para consolidação de uma cultura participativa, em comparação com as culturas súditas e de não participação. Do mesmo modo, Dalton e Klingemann (2009) sustentam que as condições sociais e econômicas tiveram um impacto específico na mobilização dos indivíduos com vista em sua participação política e eleitoral. Isto é, com o desenvolvimento das condições sociais, permitiu-se a universalização do acesso à educação e à informação, que são elementos explicativos das escolhas razoáveis dos cidadãos (INGLEHART, 1990; DALTON E KLINGEMANN, 2009).

Os autores Franklin, Mackie e Valen (1992); Howard, Barnes e Simon (1998); Dalton (1992) evidenciaram que o cidadão sofisticado, usufruiu da expansão de um conjunto de características socioeconômicas (tais como status da classe social, escolaridade, renda, etc.), tendo impacto no comportamento do eleitor e em suas preferências partidárias. De um modo geral, estes teóricos corroboram com a explicação de que no modelo de cultura política, quanto maior forem os recursos para participar (variáveis sociais e demográficas: escolaridade, sexo, etc.) maior será a participação e as escolhas razoáveis a serem feitas pelos eleitores.

Metodologicamente, trata-se de um trabalho descritivo, realizado pela junção entre as medidas de produtividade quantitativa e qualitativa, para analisar as dinâmicas da competição política e eleitoral em Moçambique. Analisamos a competição e a geografia eleitoral, a partir dos resultados eleitorais de 2014, e os dados agregados sobre as condições socioeconômicas do país, principalmente a escolaridade, que foram identificados e coletados na base de dados oficiais do Instituto Nacional de Estatística de Moçambique (INE), que no presente artigo foi operacionalizada como variável de análise determinante para melhoria dos níveis de consciência cívica em determinadas regiões de Moçambique. Do ponto de vista temporal, a nossa análise compreende os processos eleitorais realizados em Moçambique desde 1994, dando maior relevância às eleições de 2014. Em algumas passagens do texto, trouxemos episódios das eleições de 
2009, como forma de correlacionar as tendências eleitorais nas diversas regiões de Moçambique. A pesquisa também teve cunho exploratório, pelo fato de ter utilizado pesquisas empíricas e bibliográficas existentes que se referem à geografia eleitoral e aos partidos políticos em Moçambique. Nossa análise dos resultados baseou-se na modelagem e construção de tabelas e gráficos, o que nos permitiu correlacionar as variáveis de análise e a sua devida interpretação.

\section{Contexto político e partidos políticos em Moçambique}

Moçambique, como nação, resultou da guerra contra o colonizador (Portugal) levada ao fim pela FRELIMO, entre 1964 a 1974. Este processo foi auxiliado a partir das bases na retaguarda situadas na recém-independente Tanzânia (cuja orientação era socialista), assim, muito cedo, a FRELIMO se estabeleceu na região Norte de Moçambique (DE BRITO, 1995; TERENCIANO e SOUZA, 2015; TERENCIANO, 2016). Com apoio militar da China, da URSS e de outros países do bloco do Leste, a Frente expulsou os portugueses de zonas substanciais das províncias setentrionais de Tete, Niassa e Cabo Delgado. No golpe militar de 1974, em Lisboa, derrubou-se Marcelo Caetano, abrindo, assim, caminho para independência de Moçambique, em 1975, sob o poder da FRELIMO (PITCHER, 2002; MANNING, 2002; PITCHER, 2004; TERENCIANO e SOUZA, 2015; TERENCIANO, 2016). A orientação socialista da FRELIMO foi consolidada em 1977, com a adoção oficial do marxismo-leninismo pelo partido. Sob a liderança do movimento de libertação (FRELIMO), Moçambique independente, em 1977, tornou-se um Estado Socialista-Marxista de partido único, baseado nos princípios do centralismo democrático com um sistema políticoadministrativo altamente hierarquizado.

A história política e eleitoral de Moçambique foi instituída por eleições em um contexto de partido único. Por conta disto, em 1977 e em 1986, foram realizadas as primeiras e as segundas eleições no contexto do sistema de partido único, com objetivo de escolher os representantes do povo (NUVUNGA, 2007; TERENCIANO, et al, 2015). No período que prevaleceu o Partido-Estado com ideologia Marxista, conforme Pitcher (2002) e Terenciano (2016) atravessou-se um período de crise e subsequente transição e mudanças ocasionais do modelo socialista de governo, ao mesmo tempo em 
que o governo estava imerso na luta dos dezessete anos de conflito contra a RENAMO. Esta última surgiu em 1976 contra o poder centralizado da FRELIMO, cujos líderes como André Mantsangaisa e Afonso Dhlakama, organizaram desde então a resistência ao poder autoritário da FRELIMO.

O governo da FRELIMO inicia um processo de reformas econômicas, que foi acompanhado pela liberalização política. Esta passagem é ilustrada quando em 1989, no $\mathrm{V}^{\mathrm{o}}$ Congresso do Partido, a FRELIMO abandonou sua ideologia marxista-leninista transformando-se em um partido de frente mais ampla. Oponente duradoura da FRELIMO na guerra civil, a RENAMO assinou um Acordo Geral de Paz em 1992 e começou a edificar um partido político, posteriormente, iniciou a sua campanha para as eleições. No pleito de 1994, a FRELIMO ganhou com 44\% dos votos para Assembleia da República, mas a RENAMO se transformou na maior força da oposição, ganhando 38\% do voto nas eleições para a Assembleia da República em 1994 (MANNING, 2002; PHIRI, M. e MACHEVE, A, 2015, p: 38; TERENCIANO e SOUZA, 2015; VISENTINI, 2016).

\section{Quadro 1:}

Sistema Eleitoral e Partidário de Moçambique (1994 a 2014)

\begin{tabular}{|c|c|}
\hline & Moçambique \\
\hline $\begin{array}{c}\text { Sistema } \\
\text { Eleitoral }\end{array}$ & $\begin{array}{l}\text { - Representação Proporcional para Parlamento; lista fechada com distritos } \\
\text { que variam em sua magnitude: sendo } 250 \text { assentos parlamentares. Os } \\
\text { distritos com maior magnitude eleitoral, a distribuição de assentos variam } \\
\text { entre } 49 \text { e } 52 \text {. E os de menor magnitude variam de } 10 \text { a } 14 \text { assentos } \\
\text { - Majoritário de dois turnos para presidente (não há segundo turno caso } \\
\text { um candidato receba } 50 \%+1 \text { voto) }\end{array}$ \\
\hline $\begin{array}{c}\text { Sistema } \\
\text { Partidário }\end{array}$ & $\begin{array}{l}\text { - Dominante (1994 a 2014) FRELIMO, com uma tendência ao } \\
\text { Bipartidarismo (1994 à 1999); } \\
\text { - Tendência a quase dois partidos e meio (1994; } 2009 \text { e 2014). }\end{array}$ \\
\hline
\end{tabular}

Fonte: Compilado pelos autores. Base dos dados da African Elections Data Base (http://africanelections.tripod.com) 2016.

\section{Dinâmicas das eleições gerais de 2014 na Região Centro de Moçambique}

As eleições de 2014 trouxeram um dado muito importante, viu-se, pela primeira vez, que um determinado partido vence as eleições em dado distrito eleitoral, contrariamente o seu candidato perde neste mesmo distrito. Considerando os padrões de votação nas eleições de 2014 em Moçambique, este fenômeno aconteceu em dois 
distritos eleitorais com considerável magnitude eleitoral (Nampula e Tete). Verificouseque o candidato presidencial da RENAMO Afonso Dhlakama venceu as eleições, e em contrapartida, a FRELIMO venceu as eleições legislativas. De outra maneira, a FRELIMO venceu as eleições legislativas nestes distritos eleitorais supracitados, mas o seu candidato governista foi derrotado, conforme pode ser verificado a seguir.

\section{Gráfico 1:}

\section{Desempenho eleitoral dos candidatos presidenciais na Região Central - 2014}

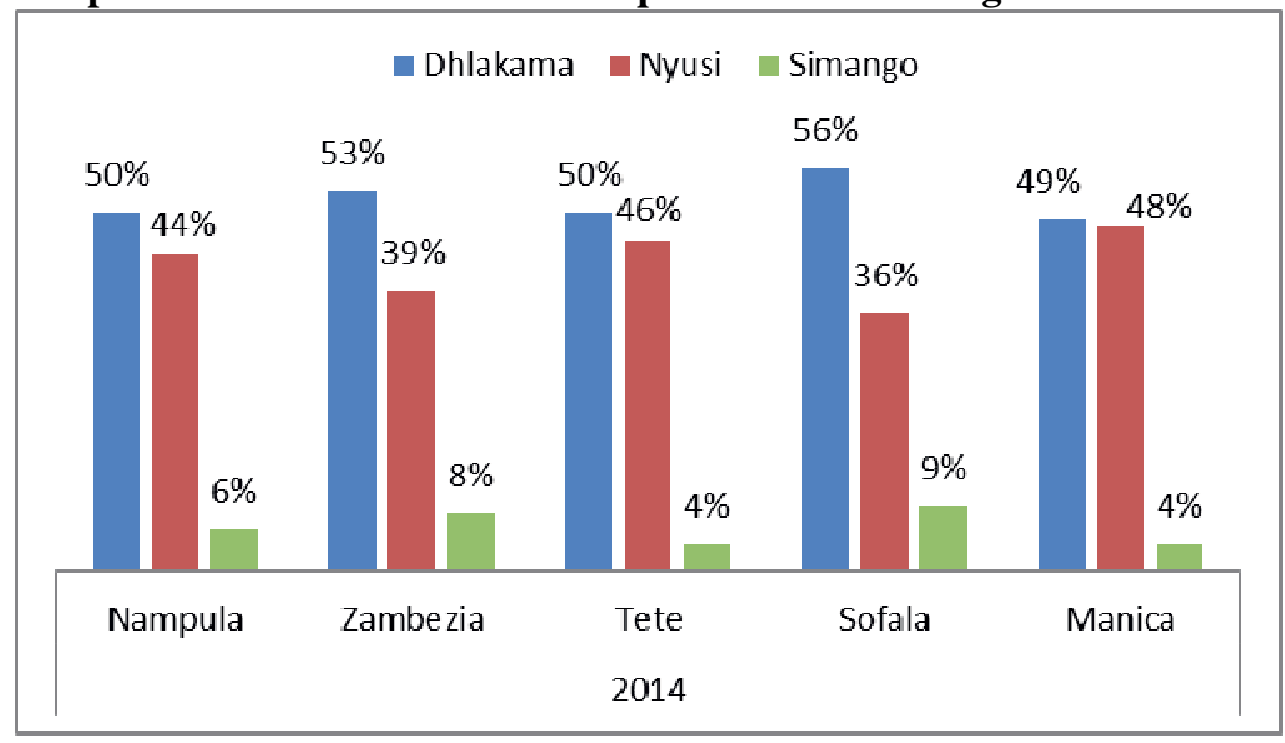

Fonte: CNE-STAE. Adaptado pelos autores (2016).

Em termos da votação nacional, o candidato da RENAMO ganhou as eleições presidenciais nos distritos eleitorais de Nampula, Tete, Zambézia, Manica e Sofala, não ocorrendo o mesmo com o partido no qual é presidente, que saiu derrotado em Nampula e Tete, como iremos evidenciar no decorrer da análise. Ora, nos distritos eleitorais de dominância da RENAMO, uma das razões da perda do voto deste partido foi a alta variação na estruturação do voto, principalmente entre os eleitores da RENAMO. De outro modo, o fato do partido MDM ter tido visibilidade considerável em termos de atuação na última legislatura (2009-2014), com destaque "as propostas de lei sobre não partidarização das instituições públicas que o partido apresentou no parlamento em 2014 e a postura dos seus deputados durante as votações sobre a reforma eleitoral em Moçambique em 2013, e outras" terão influenciado nesta variação em termos de votação. O MDM conseguiu votação considerável nos distritos eleitorais da região 
central, Tete, Zambézia, Sofala e Manica, na região norte, o maior distrito eleitoral de Moçambique - Nampula, que desde as primeiras eleições multipartidárias em Moçambique foi favorável ao partido RENAMO (NUVUNGA, 2013; TERENCIANO, 2016), conforme se verifica a seguir.

\section{Gráfico 2:}

\section{Desempenho eleitoral dos Partidos Políticos na Região Central - 2014}

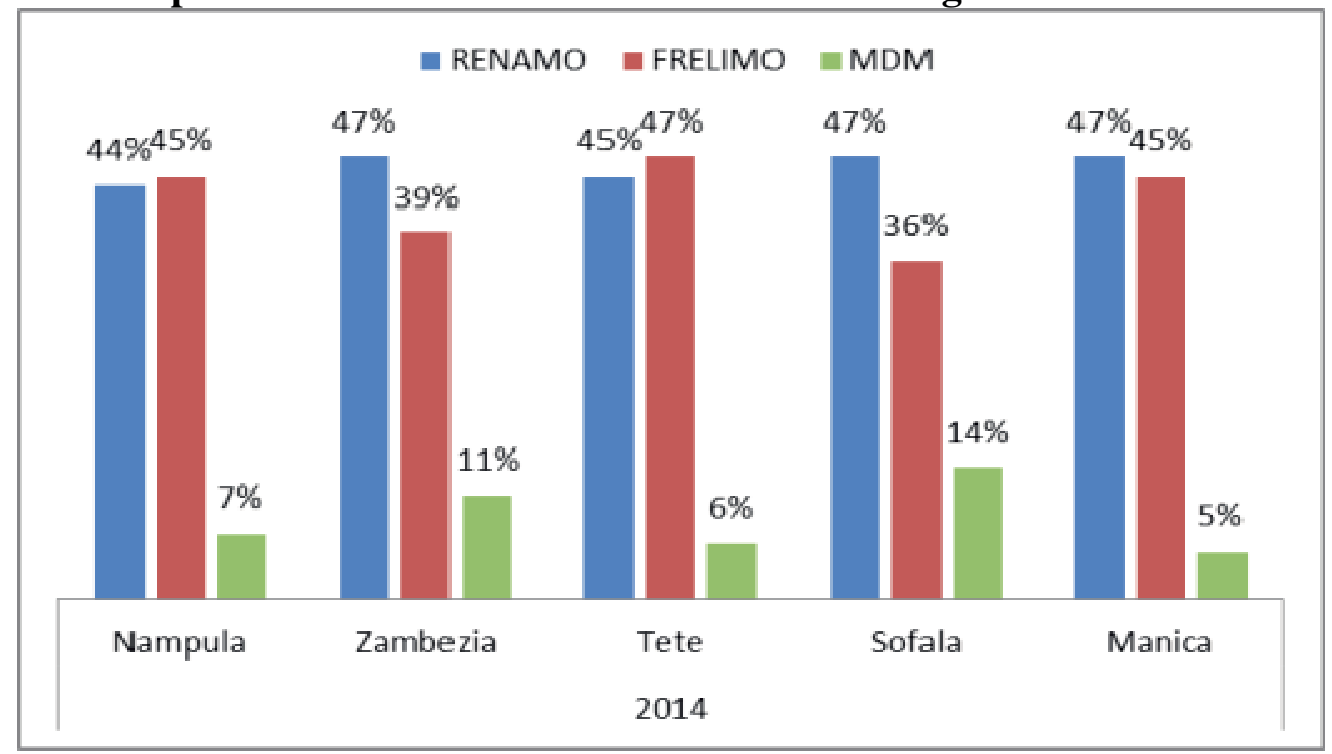

Fonte: CNE-STAE. Adaptado pelos autores, 2016.

Verifica-se uma razoável ascensão do partido MDM nas regiões onde o candidato da RENAMO foi vitorioso. É necessário destacar que o MDM é um novo partido, criado em 2008, procurando consolidar-se no sistema competitivo institucionalizado de Moçambique. Salientamos que a institucionalização da competição política e partidária a que nos referenciamos, é aquela fundamentada por Manwaring e Scully (1995); Ware (1996); Panebianco (2005), a qual, a competição endógena e exógena constitui em si uma condição da existência da democracia eleitoral. A FRELIMO e o seu candidato presidencial conseguiram manter linearmente seu apoio eleitoral nas regiões do centro de Moçambique, onde, historicamente, a oposição tem maior influência (BRITO, 1994; NUVUNGA, 2013; TERENCIANO, 2016). Os padrões de votação nas eleições de 2014, sobretudo na região central do país, vêm reforçar a tese que indica que a FRELIMO tem conseguido manter ou aumentar o seu apoio eleitoral nas regiões historicamente de predominância da RENAMO, contudo o 
mesmo não ocorre nas regiões com grande influência da FRELIMO, onde a oposição não consegue ter $10 \%$ do total da votação. Este fenômeno verifica-se com maior frequência nas províncias do sul do país (Gaza e Inhambane), e Norte - Cabo Delgado (DE BRITO, 1995a; 2014b; TERENCIANO, 2016).

Conforme evidenciam os gráficos 1 e 2 , houve uma "pseudo" mudança nas escolhas eleitorais (CRIDDLE, 1999) nas eleições de 2014 em Moçambique, resultante da mudança estrutural das condições socioeconômicas, com destaque para o aumento de escolaridade na região central de Moçambique, comparativamente às demais regiões de Moçambique, como iremos evidenciar mais a frente. A nossa análise sobre as razões das variações nas escolhas eleitorais na região central de Moçambique, incluindo Nampula, traz a seguinte explicação: o aumento do nível de escolaridade, mensurado com base no número de escolas de ensino secundário do $2^{\circ}$ ciclo existentes em cada província de Moçambique (INE, 2013), teve um impacto significativo no aumento da consciência cívica dos cidadãos nas regiões com altas taxas de escolaridade. Esta abordagem teórica e empírica já é desenvolvida na literatura da Ciência Política, destacando os estudos de Howard, Barnes e Simon (1998) e Dalton (1992).

Os dados estatísticos do INE evidenciam que as províncias de Nampula e Zambézia foram as regiões do país que tiveram um crescimento muito significativo no número de escolas de ensino secundário, comparativamente com as demais regiões do país, ao mesmo tempo em que foram as regiões em que os cidadãos tiveram um comportamento variável em termos de escolhas eleitorais. Como apontado acima, pela primeira vez, estes cidadãos nestas províncias, conseguiram atribuir seu voto de forma diferencial tanto para os candidatos como para os partidos.

A variável escolaridade é um fator determinante no aumento da consciência cívica dos eleitores, conforme Howard, Barnes e Simon (1998), entretanto, em determinadas regiões de Moçambique (Manica e Sofala) que, em termos de distribuição de escolas secundárias (até 2013), estão em posição intermediária, os níveis de variação nas escolhas eleitorais foram similares aos das regiões de Nampula e Zambézia. Neste momento, trazemos a explicação sócio-histórica, demonstrada por Brito (1995) e Terenciano (2016), que argumentam que a história política de Moçambique evidencia que a regiões do central de Moçambique foram hostis a FRELIMO. Devido ao fato de que foi nesta região do país que as políticas do partido-Estado FRELIMO, ainda no 
período socialista e marxista, como "Política de as aldeias comunas; As políticas de terras de cultivo coletivo" tiveram maior oposição popular. Esta hostilidade fundamentada pela história do país, também explica as raízes sociais dos principais partidos da oposição, RENAMO, MDM, pois estes tiveram origem na região central do país (CHICHAVA, 2010; LUNDIN, 1995; MACAGNO, 2009; CAHEN, 2009; TERENCIANO, 2016).

\section{Tabela 1:}

Escolas Públicas de ensino Secundário do $2^{\circ}$ Grau por Províncias de Moçambique (2013)

\begin{tabular}{cc}
\hline Província & $\begin{array}{c}\mathbf{N}^{\mathbf{0}} \text { Total de Escolas Secundaria por } \\
\text { Província }\end{array}$ \\
\hline Cabo Delgado & 30 \\
Niassa & 34 \\
Inhambane & 54 \\
Maputo Província & 44 \\
Sofala & 44 \\
Manica & 52 \\
Maputo Cidade & 55 \\
Gaza & 58 \\
Tete & 58 \\
Zambézia & 87 \\
Nampula & 116 \\
\hline Total & $\mathbf{6 3 2}$
\end{tabular}

Fonte: Ministério da Educação de Moçambique, 2013. Adaptado pelos autores (2016).

A educação constitui um instrumento fundamental, sendo responsável, em grande, parte para materialização dos fundamentos básicos e direitos civis, políticos e sociais dos cidadãos (PINTASSILGO, 1998; MONTEIRO, 2001), ao mesmo tempo, cria possibilidades para o cidadão se informar com qualidade e poder intervir na vida política de forma ativa. O estudo realizado por Pintassilgo (1998) chega à conclusão de que a educação sempre desempenhou um papel importante no aumento da consciência cívica e política dos cidadãos, sempre inter-relacionada com a disponibilidade de informação (PIPPA, 2011) e mudança das condições estruturais da sociedade (DALTON, 2009, p. 60; PIPPA, 2011; VERBA E KIM, 1972; PUTNAN, 2000) por via da modernização social. Além disso, se o cidadão tiver uma consciência cívica e política delineada com base em informações razoáveis (DALTON, 1992; MOPHIE, 1954), em períodos eleitorais, ele passa a ser um eleitor mediano e coloca-se na condição de fazer 
escolhas a partir do que o partido governista fez em termos de outputs, e o que espera que faça caso vença as eleições, isto é, análise de custos e benefícios, por via do voto retrospectivo (FIORINA, 1976) e prospectivo (KEY Jr., 1966).

Ora, se o nível de escolaridade aumenta os níveis de consciência cívica, então as províncias de Nampula e Zambézia são passíveis de serem analisadas sob este ponto de vista, como sendo aquelas que aumentaram consideravelmente a consciência cívica em termos de participação política e escolhas eleitorais, que associamos a educação como fator explicativo. Nestes termos, alguns exemplos podem ser apontados: um sistema eleitoral com voto facultativo, listas fechadas, que cria cada vez mais distanciamento entre o agente e o principal, propiciando o surgimento de vários cenários: hipoteticamente o cidadão com um nível de educação e com informação razoável sobre o funcionamento do sistema político e tem conhecimento que a abstenção eleitoral não é penalizada por lei, simplesmente opta por não votar, pois em termos práticos isso não traz benefícios materiais para sua sobrevivência. Ou porque não vai mudar o rumo do resultado eleitoral, ou pelo comodismo que as coisas vão continuar como estão mesmo participando ou não.

Conforme indicado, a regiões do central de Moçambique, especificamente Zambézia, Sofala e Nampula, nunca simpatizaram com o partido FRELIMO e seus candidatos, com a exceção das eleições de 2004 e 2009, nas quais o candidato governista Armando Guebuza ganhou nos distritos eleitorais de Nampula, Tete e Manica, que são fortes redutos da RENAMO desde as primeiras eleições de 1994 (TERENCIANO, 2016; BRITO, 2014). Uma possível explicação do revés dos padrões de votação em 2004 e 2009 foi a novidade de que Armando Guebuza, candidato governista, ser natural de Nampula, região norte do país, e isso gerou um debate muito forte nas vésperas das eleições de 2004. Duas razões explicam este fenômeno: primeiro, o fato de que, desde a fundação da FRELIMO em 1962, os presidentes desta agremiação política sempre terem sido do sul do país, e os membros do partido oriundos da região centro e norte, normalmente relegados para outros postos dentro do partido. Segundo, havia um debate interno no seio da FRELIMO, que fez surgir vozes internas em que o candidato deveria ser do norte ou do centro do país. 


\section{Geografia eleitoral da vitória do candidato governista nas presidências de 2014}

Analisar a geografia eleitoral de uma determinada coletividade deve ser associado à trajetória histórica das relações de poder e identidades políticas da coletividade (MOLINA, 1998). Os estudos pioneiros da geografia eleitoral (SIEGFRIEND, 1913; SEUER, 1918) relacionavam a influência do espaço geográfico na orientação política dos eleitores (ZOLNERKEVIC, 2011, p. 2). Neste contexto, estudar geografia eleitoral das eleições em Moçambique, em particular das últimas eleições, apresenta-se relevante para compreender tanto as zonas de dominância de cada partido ou candidato quanto aos fatores explicativos.

Desde as primeiras eleições multipartidárias de 1994, os candidatos do partido FRELIMO venceram sempre as eleições, tiveram sempre regiões de dominância nítida, ao mesmo tempo em que existiam regiões de dominância do candidato da RENAMO. Em parte, isso mostra como o campo político moçambicano está distribuído em termos de padrões de votação: A FRELIMO domina todas as províncias da zona sul do país e o extremo-norte, inversamente, a RENAMO domina a zona central e centro-norte do país (DE BRITO, 2014, p: 31; TERENCIANO, 2016). Entretanto, o que se verificou nas últimas eleições de 2014 foi uma reestruturação das zonas de dominância dos candidatos dos principais partidos.

Em um estudo, Trigal e Del Pozo (1999, p. 196), Soares e Terron (2008, p. 275), analisam a geografia política a partir da competição eleitoral, e propõem três elementos explicativos: 1- A explicação dos mapas para estudar as tendências do voto em áreas concretas; 2- O papel dos fatores espaciais no comportamento eleitoral; 3- A delimitação dos distritos eleitorais que dá origem a uma geografia da representação com resultados notáveis nos países com sistema eleitoral majoritário. A partir da caracterização das tipologias que o estudo da geografia eleitoral nos possibilita, nesta parte do artigo nos propomos a iniciar uma análise da geografia eleitoral das últimas eleições presidências de 2014, focalizando os padrões verificados em cada distrito eleitoral. Aqui, buscamos descrever as regiões que o candidato teve maior apoio eleitoral, vis-à-vis as regiões em que o mesmo saiu derrotado pelo candidato da oposição Dhlakama. 


\section{Moçambique: um campo político enigmático?}

Desde a constituição multipartidária de 1990 que institui a democracia e a competição eleitoral em 1994, Moçambique vem realizando eleições multipartidárias de cinco em cinco anos, nas quais o candidato da FRELIMO sempre venceu. Todavia, houveram eleições que a FRELIMO não conseguiu estruturar preferências eleitorais que levassem a vitória majoritária. Exemplificamos os pleitos de 1999, que tiveram uma particularidade, pois um conjunto de estudos (BRITO, 2014; HANLON, 2000; TERENCIANO, 2016) apresentaram dados que comprovam que o candidato da FRELIMO não perdeu as eleições para o Dhlakama, então não é menos verdade que poderiam ter existido fraudes ou falta de transparências eleitorais que modificaram a tendência inicial dos resultados eleitorais. Como pode se ver no gráfico a seguir,

\section{Gráfico 3:}

Desempenho dos candidatos a Presidência (1994-2014)

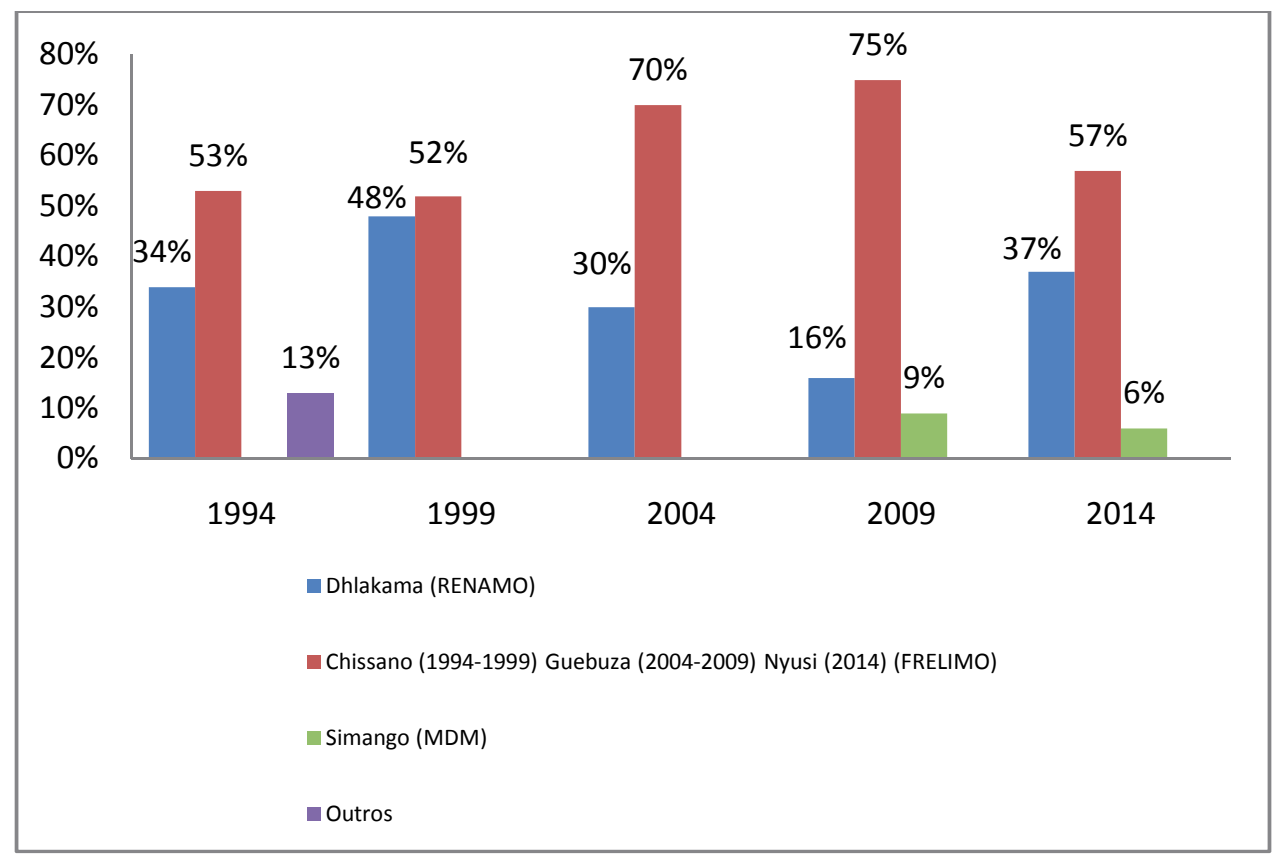

Fonte: CNE-STAE. Adaptado pelos autores (2016).

Alguns autores apresentam dados eleitorais que explicam o cenário da competição política nas eleições de 1999, 
[...] Apesar das vitorias sucessivas da FRELIMO, o maior partido da oposição, a RENAMO, nunca reconheceu oficialmente os resultados de todas as eleições até então realizadas em Moçambique. Como tal, o Líder Afonso Dhlakama, tem sucessivamente contestando os resultados eleitorais e as vitorias a favor do candidato e o partido FRELIMO, alegando a fraude e falta de transparência na gestão do processo eleitoral. Se bem que há duvidas, ao menos as eleições de 1999, dão ainda mais margens de duvida. Por quê? Porque naquelas eleições, houve centenas de milhar de votos da Zambézia e Nampula (regiões que compõem os dois maiores círculos eleitorais do País e particularmente favoráveis à RENAMO), que não foram contabilizados, Dhlakama, teve 2133665 votos (48\%), contra 2338333 votos (52\%) para Chissano, do partido FRELIMO que conseguiu se reeleger. Mas uma situação deixa duvidosa, visto que os votos que não foram contabilizados (quase 300 000 mil votos), em si, correspondiam a $8 \%$ do total da votação. Sendo a uma região de domínio da RENAMO, permite ainda mais dúvidas se o candidato da oposição não teria realmente ganho as eleições [...] (HANLON, 2000; DE BRITO, 2014; TERENCIANO, 2016).

Os padrões da competição política reconfiguram-se a partir de 2004, quando entrou em cena o novo presidente da FRELIMO, Armando Guebuza. Por muitos visto como presidente do partido e candidato que conseguiu minimizar a crise interna da FRELIMO e a tendência expansiva da RENAMO do ponto de vista de estruturação de preferências eleitorais (BRITO, 2014). Isso se comprova em termos da votação favorável ao candidato da FRELIMO nas presidências de 2004 e 2009, que consegue recuperar ou equilibrar a votação nos distritos eleitorais favoráveis historicamente a RENAMO (Manica e Nampula), do mesmo modo, consegue controlar a província de Tete, conforme pode se ver:

\section{Tabela 2:}

Desempenho dos candidatos presidenciais em Distritos Eleitorais favoráveis a RENAMO (1994-2009)

\begin{tabular}{c|l|l|l|l|l|l}
\hline \multirow{2}{*}{$\begin{array}{c}\text { Distrito } \\
\text { Ano }\end{array}$} & \multicolumn{2}{c|}{ Nampula } & \multicolumn{2}{c|}{ Tete } & \multicolumn{2}{c}{ Manica } \\
\cline { 2 - 7 } & Dhlakama* & Chissano** & Dhlakama & Chissano & Dhlakama & Chissano \\
\hline $\mathbf{1 9 9 4}$ & $43 \%$ & $38 \%$ & $42 \%$ & $41 \%$ & $50 \%$ & $34 \%$ \\
$\mathbf{1 9 9 9}$ & $48 \%$ & $38 \%$ & $53 \%$ & $36 \%$ & $60 \%$ & $31 \%$ \\
\cline { 2 - 7 } & Dhlakama & Guebuza*** & Dhlakama & Guebuza & Dhlakama & Guebuza \\
\cline { 2 - 7 } $\mathbf{2 0 0 4}$ & $40 \%$ & $45 \%$ & $21 \%$ & $69 \%$ & $45 \%$ & $45 \%$ \\
$\mathbf{2 0 0 9}$ & $24 \%$ & $58 \%$ & $8 \%$ & $79 \%$ & $20 \%$ & $63 \%$ \\
\hline
\end{tabular}

Fonte: CNE-STAE. Adaptado pelos autores (2016)

Candidato presidencial da RENAMO desde 1994 a 2014 (*Dhlakama)

Candidato presidencial da FRELIMO desde 1994 a 2009 (**Chissano) 2004 a $2009(* * *$ Guebuza) 
Houve um conjunto de fatores que podem explicar a perda de apoio eleitoral da RENAMO e do seu candidato nas regiões em que historicamente eram favoráveis. Primeiro, foi a revitalização dos chefes tradicionais por parte do governo da FRELIMO, considerada como política oriunda do recém-eleito Guebuza. Estes chefes locais (conforme GEFFRAY, 1992; TERENCIANO, 2016) desempenharam um papel importante na guerra civil a favor da RENAMO, sobretudo na região norte do país (cf. GEFFRAY, op. cit). Segundo, a tendência da marginalização cronológica da oposição em Moçambique, neste caso, a RENAMO. E, por último, a constante afirmação que Guebuza é natural da região norte, o que significava uma tentativa embrionária de inclusão das outras etnias no poder em Moçambique.

\section{Geografia eleitoral das presidenciais de 2014: transformando velhas tendências em novas}

Em seu texto, Castro (2011, p: 159) assegura que para entender a Geografia Eleitoral de um país, é de suma importância que se entenda o sistema político e eleitoral e como a arquitetura institucional possibilita a transformação do voto em representação, isto é, a tendência dos padrões de votação na abordagem da geografia eleitoral tem em vista explicar os resultados das eleições, correlacionando as questões espaciais e a posição do eleitor no campo de atuação das forças políticas. Portanto, desde as eleições de 1994, existiram algumas regiões com dominância do candidato do partido governista "FRELIMO", em contrapartida, existiam regiões de dominância do candidato da oposição. Deste ponto de vista, o sistema político e a competição partidária não são congelados como evidência (SCHATTSCHNEIDER, 1942; MAIR, 1996; PERES, 2013), mas se verifica uma reconfiguração da competição partidária, porém, há variações dos padrões de votação e estruturação de voto em cada distrito eleitoral.

Em 2014, o candidato governista venceu as eleições, no entanto,verifica-se que perdeu a dominância nos distritos em que seu antecessor (Guebuza) venceu nas eleições de 2004 e 2009. Nas mesmas eleições, Dhlakama que vinha perdendo o apoio eleitoral em algumas regiões, onde nos pleitos de 1994 e 1999 teve amplo apoio, porém, conseguiu recuperar-se (Nampula, Zambézia, Sofala, Tete). 
Tabela 3:

Desempenho Eleitoral de Nyusi e Dhlakama nas presidências de 2014

\begin{tabular}{cccc}
\hline Região & Províncias & Dhlakama & Nyusi \\
\hline NORTE & Cabo Delgado & $18 \%$ & $78 \%$ \\
$=$ & Niassa & $44 \%$ & $49 \%$ \\
$=$ & Nampula & $50 \%$ & $44 \%$ \\
\hline CENTRO & Zambézia & $53 \%$ & $39 \%$ \\
$=$ & Sofala & $56 \%$ & $36 \%$ \\
$=$ & Tete & $50 \%$ & $46 \%$ \\
$=$ & Manica & $49 \%$ & $48 \%$ \\
SUL & Inhambane & $19 \%$ & $76 \%$ \\
$=$ & Gaza & $3 \%$ & $94 \%$ \\
$=$ & Maputo Cidade & $21 \%$ & $69 \%$ \\
$=$ & Maputo Província & $18 \%$ & $74 \%$ \\
\hline
\end{tabular}

Fonte: CNE-STAE. Adaptado pelos autores (2016).

Algumas regiões que nas últimas eleições de 2004 e 2009, estiveram no controle do partido FRELIMO e seu candidato, especificamente Tete, Nampula, Niassa e Manica, foram reconquistadas pelo partido RENAMO e o seu candidato ( $c f$. Tabela 2). Esta distribuição da geografia eleitoral já foi tendência nas primeiras e segundas eleições multipartidárias em Moçambique, isto é, quando a RENAMO em 1994 e 1999 teve um apoio eleitoral nas províncias de Tete, Niassa, Nampula e Manica, contudo, em 2004 e 2009, quando Guebuza revitalizou sua força eleitoral.

Deste modo, Nyusi perdeu o maior distrito eleitoral de Moçambique Nampula, Tete voltou para Dhlakama, Manica, configurando um empate técnico, e Niassa uma vitória apertada de Nyusi. Um aspecto a salientar é o revés na província de Tete em que o candidato da RENAMO em 2009, havia conseguido 8\% da votação. Ao mesmo tempo em que Nyusi continuou vitorioso nas regiões de dominância histórica da FRELIMO, mantendo a linha histórica das vitórias nas seguintes regiões: Cabo Delgado, Gaza, Inhambane e Maputo Província e Cidade de Maputo. 


\section{Gráfico 4:}

Média percentual da vitória de Nyusi nas três regiões do País

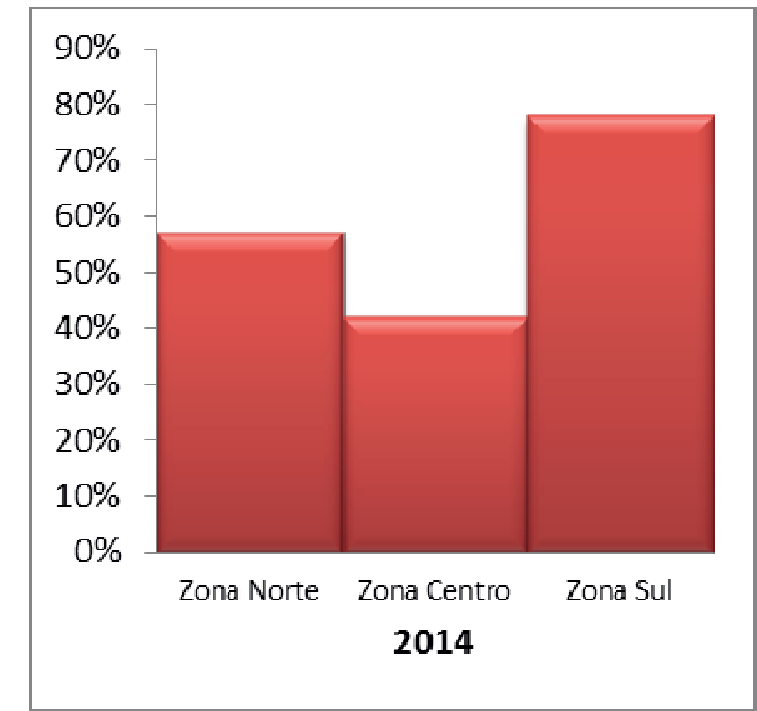

Fonte: CNE-STAE. Adaptado pelos autores (2016)

Consideramos que a tese de existência de zonas de dominância de cada partido, se verifica em parte. Por um lado, em razão da região norte do país ser favorável ao partido FRELIMO, com maior significância nas eleições de 2004 e 2009, mas com ligeiro abrandamento nas eleições de 2014. E por outro lado, a região sul do país sempre apoiadora, em termos eleitorais ao partido FRELIMO e seus candidatos, continua tênue a seu favor, que não se diferencia muito dos resultados dos pleitos de 1994 a 2009, nos quais os candidatos da FRELIMO sempre conseguiram maioria absoluta de votos.

\section{É momento oportuno para uma reforma política - eleitoral em Moçambique?}

Moçambique faz parte da lista dos países considerados democracias da terceira onda (HUNTINGTON, 1994; O’DONNELL, 1988; DIAMOND, 2002). Um dos elementos que caracterizam as nações das democracias africanas recentes é a permanência no poder dos grupos que levaram o país à independência; ausência de alternância no poder; e forte relação entre o executivo e legislativo, pois na maioria dos países o sistema de governo é presidencialista. Vale ressaltar que nessas democracias, as reformas políticas são escassas e os anseios das populações muita vezes não são representados pelos parlamentares, pois a principal preocupação destes é a política 
individualista (BADIE, 1992) ou apenas a de satisfazer as obrigações do partido (ELISCHER, 2013; KADIMA, 2009).

Autores como Avritzer e Anastasia (2006) compreendem a reforma política como uma forma de reorganização de regras para competições eleitorais periódicas. Como não é fácil descrever com precisão quais são realmente as razões das contínuas crises cíclicas do quadro político e eleitoral em Moçambique, observando-se entre elas, o fato da RENAMO contestar os resultados eleitorais de todos os pleitos até então realizados; Nunca legitimou a vitória da FRELIMO desde 1994; Manifestações dos membros da RENAMO em 2000, que levaram a morte de um conjunto de apoiadores na província de Cabo Delgado; Alguns focos de conflito armado entre as forças armadas de defesa de Moçambique e os homens armados da RENAMO desde 2012 até atualmente, bem como o fato de muitos cidadãos não conhecerem seus representantes. Aqui associamos a tese do declínio dos partidos, perceptível em termos de distanciamento entre os partidos e os interesses da sociedade como um todo segundo os resultados da pesquisa Afrobarometer (2015) e teoricamente evidenciadas por Dalton (2013), Mair (1993) e Aldrich (1995).

Outras razões que evidenciam a necessidade de uma reforma política em Moçambique, que não só incluem as dinâmicas eleitorais, mas também o funcionamento do sistema político como um todo, a nosso ver, hoje é um sistema político e partidário que não representa maior parte dos anseios das populações. Um sistema político e eleitoral insustentável em que Moçambique vive (crises cíclicas político e militar), o sistema eleitoral de representação proporcional de lista fechada, voto obrigatório e Estado unitário já não satisfaz os anseios das populações. Baixa confiança política (Afrobarometer, 2015), falta de consenso entre os principais partidos FRELIMO e RENAMO, mensurável a partir da atuação dos dois no Congresso Moçambicano. Tendo em vista, pragmatismo (Situação vs. Oposição) e a falta de senso de responsabilidade do governo em termos da democracia representativa na linhagem de accountability (PUTKIN, 1997; PRZEWORSKI, STOKES E MANIN, 1999; NORRIS, 2011).

Nossa proposta é que as crises cíclicas em Moçambique possam encontrar sua saída reconsiderando uma reforma do quadro político e eleitoral que inclui:

1. Abertura para um sistema eleitoral de listas abertas, seguida de um regimento que sustentaria a Lei Eleitoral. É nossa proposta, uma lei eleitoral que criaria 
enforcement, o qual somente pode candidatar-se para representantes do povo, cidadãos que vivem em determinado distrito eleitoral com um mínimo de 10 anos (aqui assumimos que os candidatos conhecem os reais problemas da população);

2. A reforma política e eleitoral deve suprimir a representação por listas fechadas, pois isso permite que os candidatos parlamentares obtenham coeficiente eleitoral a partir da votação do partido;

3. Eliminação da cláusula de barreira dos $5 \%$ da votação nacional, que, na nossa visão, dificulta os pequenos partidos no alcance do coeficiente eleitoral e alcance de representação parlamentar no congresso moçambicano. Se isso não é possível, ao menos, que as populações tenham sensação de que votam constantemente nos pequenos partidos e sentem que influenciam nas decisões governamentais.

\section{Considerações finais}

Este artigo discutiu os pontos paradoxais sobre as dinâmicas da competição política e eleitoral em Moçambique nas eleições de 2014, partindo do pressuposto histórico-comparativo, entendemos que as eleições em Moçambique constituem uma instituição pela qual se renovação da elite política de forma institucionalizada. As eleições são reguladas por lei própria, que reflete os anseios dos Acordos Gerais de Paz de 1992.

$\mathrm{Na}$ análise dos padrões de votação e geografia eleitoral em Moçambique, é possível aferir duas situações: que as razões explicativas da distribuição da competição política em Moçambique são oriundas da história política de Moçambique, ao mesmo tempo em que nas eleições de 2014 ocorreu uma espécie de reestruturação do campo político e eleitoral, que permitiu ao candidato da RENAMO recuperar algumas zonas de dominância histórica desde 1994. Mapeando os dados eleitorais das últimas eleições de 2014, o candidato governista perdeu hegemonia que seu antecessor teria conquistado nas regiões historicamente dominadas pela RENAMO, mas conseguiu vencer as eleições como demonstrado em tabelas e gráficos ao longo do texto. 
A educação constituiu um elemento explicativo do aumento da consciência política dos cidadãos em várias regiões de Moçambique, com destaque às regiões de dominância da RENAMO. Ao mesmo tempo em que esta análise considerou importante a influência da história política do país, principalmente no período do governo socialista-marxista da FRELIMO, como sendo uma das razões explicativas do avanço significativo da consciência cívica na região central do país, e a partir disto analisamos que pela primeira vez os eleitores em dadas regiões de Moçambique conseguiram atribuir seu voto de forma distinta. De um lado, votando no candidato da RENAMO, de outro lado votando no partido diferente do candidato de sua escolha, neste caso, o partido FRELIMO. Neste contexto, no final do artigo, trazemos algumas propostas para a reforma política em Moçambique, entendendo que há necessidade dos moçambicanos, como um todo (pobres, ricos, intelectuais, partidos políticos, sociedade civil), unir esforços no sentido comum, que é procurar constantemente o consenso político, que deve resultar do processo deliberativo (LIJPHART, 1999). Isto quer dizer que, a reforma política e eleitoral pode levar Moçambique a percorrer o caminho duradouro da convivência pacifica e inclusiva, e assim eliminar as crises cíclicas.

\section{Referências}

AFROBAROMETER. Survey Overview the Quality of Democracy and Governance in Mozambique. Afrobarometer Round 6, 2014-2015. Compiled by: Ipsos Mozambique Ltd. 2015.

ALMOND, G.; VERBA, S. The Civic Culture: Political Attitudes and Democracy in Five Nations. Princeton: Princeton University Press. 1963.

ANASTASIA, F.; NUNES, F. A reforma da Representação. In AVRITZER, L. e ANASTASIA, F. (Org). Reforma Política no Brasil. Belo Horizonte: Editora UFMG, 2006. p. 17-29.

AVRITZER, L.; ANASTASIA, F. (Org). Reforma Política no Brasil. Belo Horizonte: Editora UFMG. 2006.

ANTUNES, R. Identificação Partidária e Comportamento Eleitoral: Factores Estruturais, Atitudes e Mudanças no Sentido Do Voto. Coimbra. 2008. 
BARTELS, L. Uninformed Votes: Information Effects In Presidential Elections. American Journal Of Political Science, 40. 1996

BADIE, B. L'Etat importé. Essai sur l'occidentalisation de l'ordre politique. Paris, Fayard, 1992,

BOND, R et al. A 61-Million-Person Experiment in Social Influence And Political Mobilization.Nature, 489. 2012.

BRITO, L. De. O Comportamento Eleitoral nas Primeiras Eleições Multipartidárias em Moçambique. In: B. Mazula, ed. Moçambique, Eleições, Democracia e Desenvolvimento. Maputo. 1995.

; Uma Reflexão Sobre o Desafio da Paz em Moçambique. In Desafios para Moçambique 2014. Org. Luís de Brito; Carlos Nuno Castel Branco et al. Maputo, 2014.

CAHEN, M. Check on Socialism in Mozambique - What Check? What Socialism? Review of African Political Economy 57.1993. p. 46-59. Cambridge University Press. 2011.

CARRILHO, N. A legislação eleitoral em Moçambique e a realização política e social. In: B. Mazula, ed. Moçambique, Eleições, Democracia e Desenvolvimento. Maputo. 1995.

CASTRO, I. Geografia e Política: território, escalas de ação e instituições. $4^{\mathrm{a}}$ ed. Rio de Janeiro: Bertrand Brasil, 2011.

CHICHAVA, S. Movimento Democrático de Moçambique: uma nova força política na democracia moçambicana? Instituto de Estudos Sociais e Económicos (IESE) Maputo, Moçambique, 2010.

DALTON, R. Citizen Politics. Washington, DC: Congressional Quarterly Press. 2008.

DALTON, R.; KLINGEMANN, H. Overview of Political Behavior: Political Behavior and Citizen Politics. In: Robert Goodin (ed.). Oxford Handbook of Political Science. Oxford: Oxford University Press, cap. 17, 2009. p. 321-344.

ELDERSVELD, S. Political Parties: a behavioral analysis. Chicago: R. McNally e Co. 1966.

ELISCHER, S.The Diversity of African Party Politics. In Political parties in Africa: ethnicity and party formation. 2013. 
FIGUEIREDO, M. A Decisão Do Voto: Democracia e Racionalidade. São Paulo: Ed. Sumaré. 1992.

FIORINA, M. Retrospetive voting in American national electoral. New Haven: Yale University Press, 1981.

FRANKLIN, M.; MACKIE, T.; VALEN, H. Electoral change: Responses to evolving social and attitudinal structures in Western Countries. Cambridge: Cambidge University Press. 1992.

GEFFRAY, C. A Causa das Armas. Porto, Edições Afrontamento. 1991.

HARDER, J.; KROSNICK, J.Why Do People Vote? A Psychological Analysis Of The Causes Of Voter Turnout.Journal Of Social Issues, 64. 2008.

HUNTINGTON, S. A terceira onda: a democratização no final do século XX. São Paulo: Ática. 1994.

INGLEHART, R. Culture shift in advanced Industrial Society. Princeton: Princeton University Press. 1990.

Instituto Nacional de Estatística (INE) - Estatística e Indicadores Sociais, 2012-2013 @) 2012.

KADIMA, D. Party Coalitions in Post-Apartheid South Africa and their Impact on National Cohesion and Ideological Rapprochement. In KADIMA, D. The politics of party coalitions in Africa. 2009.

KHALIL. E. The New Behavioral Economics. Northampton, Ma: Edward Elgar. 2009

LUNDIN, I. Partidos políticos: a leitura da vertente étnico-regional no processo democrático. In: Mazula Brazão (org). Eleições, democracia e desenvolvimento. Maputo, Embaixada dos países baixos, 1995. p. 423-472.

MACAGNO, L. Fragmentos de uma imaginação nacional. RBCS Vol. 24 no 70, junho/2009.

MAINWARING, S.; SCULLY, T. A institucionalização dos Sistemas Partidários na América Latina. Dados, 37.1, 1994.

MAIR, P. Party System Change - Approaches and Interpretations. Oxford, Clarendon Press, 1997.

MANIN, B.; PRZEWORSKI, A.; STOKES, S. Eleições e representação. Lua Nova, São Paulo, n. 67, p. 105-138, 2006. 
MOLINA, I. Conceptos fundamentales de Ciencia Política. Alianza Editorial, Madrid, 1998.

MONTEIRO, A. (org). Educação para a Cidadania. Textos Internacionais Fundamentais. Lisboa. Centro de investigação em Educação da Faculdade de Ciências da Universidade de Lisboa. 2001.

NORRIS, P. Democratic Deficit: Critical Citizens Revisited. Cambridge: Cambridge University Press. 2011.

PANEBIANCO, A. Modelos de Partidos. Organização e Poder nos partidos políticos. São Paulo. Martins Fontes. 2005.

PERES, P. Institucionalização do sistema partidário ou evolução da competição? Uma proposta de interpretação econômica da volatilidade eleitoral. Revista Opinião Pública. Vol. 19, nº 1. Campinas. 2013.

PISTASSILGO, J.; MOGARRO, M. Citizenship erducation within the process of Portuguese Social Democratization. In A. Ross (ed). The Experience of Citizenship. London, CiCe Thematic Network Project. London Metropolitan University. 2004.

PITKIN H. O conceito de representação. In: CARDOSO, F e MARTINS, C. (Orgs.). Política e sociedade. São Paulo: Ed. Nacional, 1983. p. 8-22.

PUTNAM, R. Making Democracy Work: Civic Traditions in Modern Italy. Princeton: Princeton University Press. 1994.

ROSEMA, M. The Sincere Vote: A Psychological Study of Voting. Dissertation. University Of Leiden, Leiden.2004.

SÁNCHEZ, J. E. Geografía política, Síntesis, Madrid, 1992.

SANGUIN, A. L. Geografía política, Oikos-Tau, Barcelona, 1981.

SCHATTTSCHNEIDER, E. Party government. New York: Farrar and Reinhart, 1942.

SOARES, G.; TERRON, S. Dois Lulas: a geografia eleitoral da reeleição (explorando conceitos, métodos e técnicas de análise geoespacial). Opinião Pública. Campinas, vol. $14, \mathrm{n}^{\mathrm{o}} 2,2008$.

TERENCIANO, F. Competição Política e Geografia Eleitoral em Moçambique (19942014). Programa de Pós Graduação em Ciência Política - UFPA. Dissertação de Mestrado. 2016.

TRIGAL, L.; Del POZO, P. Geografia Política. In: El comportamiento electoral y lós sistemas políticos. Madrid: Cátedra, 1999. 
WARE, A. Political Parties and Party Systems. Oxford, Oxford University Press, 1996.

ZANFOLIN, D. Geografia Eleitoral: reforma política e uso do território brasileiro. Dissertação (Mestrado em Geografia Humana), USP, 2006.

Recebido em 02 de junho de 2016.

Aprovado em 12 de outubro de 2016. 